https://helda.helsinki.fi

\title{
Patient involvement in problem presentation and diagnosis delivery in primary care
}

\section{ljäs-Kallio, Taru}

2010

ljäs-Kallio , T , Ruusuvuori , J E \& Peräkylä , A 2010 , ' Patient involvement in problem presentation and diagnosis delivery in primary care ' , Communication \& Medicine , vol. 7 , no. 2 , pp. 131-141.

http://hdl.handle.net/10138/29637

publishedVersion

Downloaded from Helda, University of Helsinki institutional repository.

This is an electronic reprint of the original article.

This reprint may differ from the original in pagination and typographic detail.

Please cite the original version. 
Volume 7(2) (2010), 131-141

Copyright @ Equinox Publishing Ltd

London

http://equinoxpub.com

DOI: $10.1558 /$ cam.v7i2.131

\title{
Patient involvement in problem presentation and diagnosis delivery in primary care
}

\author{
TARU IJÄS-KALLIO ${ }^{1}$, JOHANNA RUUSUVUORI1 AND ANSSI PERÄKYLÄ² \\ (1) University of Tampere, Finland (2) University of Helsinki, Finland
}

\begin{abstract}
This article reports a conversation analytic study of primary care physicians' orientations to different types of patients' problem presentation. Four types of problem presentation are examined: 1. symptoms only; 2. candidate diagnosis; 3 . diagnosis implicative symptom description; and 4. candidate diagnosis as background information. The analysis shows that both in receiving the problem presentation at the beginning of the visit and in delivering a diagnosis later on, doctors address the patients' presentations which involved or implied a candidate diagnosis. In contrast, following a symptoms-only type of problem presentation such references predominantly are not made. The study suggests that patients' problem presentation have a crucial role in shaping the doctor's communication patterns also in the phases of consultation in which the patient's active participation is of lesser significance, such as the diagnostic phase. The findings are discussed in relation to the question of patient participation in the medical consultation. The data consist of 86 video-recorded Finnish primary care consultations for upper respiratory tract infection including both child and adult patients.
\end{abstract}

Keywords: medical communication; primary care; problem presentation; diagnosis delivery; conversation analysis

\section{Introduction}

Patient involvement and participation in medical consultations are strongly encouraged in current healthcare policies (Barry et al. 2001; Thompson 2007). However, in actual face-to-face encounters it is difficult to grasp how patients actually participate and are able to share their views with their doctors (Stevenson et al. 2000; Bissel et al. 2004; Collins et al. 2007). The present article shows how patient participation is realized in the details of talk-in-interaction between doctors and patients. We show how patients' views of their conditions are put forward at the initial phase of the encounter and how these views are oriented to by doctors in ways that shape the communication in the consultation.

Medical consultation follows a trajectory of activities. This was first described by Byrne and Long (1984 [1976]) who discerned doctors' behaviours in six phases of consultation: 1 . relating to the patient; 2 . discovering the reason for the patient's attendance; 3 . conducting a verbal and/or physical examination; 4 . consideration of the patient's condition; 5 . detailing treatment or further investigation; and 6. terminating the visit (Byrne and Long 1984 [1976]: 21-29). Later on, interaction studies have shown that this overall structure informs both doctors' and patients' actions in the visit (Robinson 2003; Heritage and Maynard 2006). It has also been shown that the overall structure of the medical consultation resembles that of a service encounter. By presenting their problem to the doctor, patients make a request for service, questioning the medical expert about their medical concern and its treatment. In turn, by diagnosing the patient's problem and suggesting a treatment doctors respond to the initial request, i.e. grant the service asked for (Ruusuvuori 2000: 84; Heritage and Maynard 2006).

However, there is variation in how patients make their initial requests. In addition to the description of symptoms, problem presentations often include affective or moral accounts of the patient's agency as well as the patient's own explanations of illnesses (Ruusuvuori 2000; ten Have 2001; Stivers 2002; Roberts et al. 2004). Accordingly, there is variation 
in how doctors respond to patients' initial requests. In paediatric consultations in the USA, Stivers (2002) found that by presenting 'symptoms only', parents were perceived by doctors as expecting an evaluation of their child. In turn, by presenting candidate diagnoses parents were perceived by doctors as seeking confirmation of the proposed diagnosis and, importantly, treatment for it. In Stivers' (2002) research one important finding was that the doctors' perceptions of their patients' expectations were not always correct. A more focal observation in this article is that: (a) patients are perceived by doctors to have specific aims or views with regard to the outcome of the consultation and that these views are embedded in their initial problem presentation; and (b) doctors take these views into account in their consequent actions in the consultation.

This article offers an empirical account of how patients' views are involved in the communicative conduct in primary care consultations. We show that doctors establish an understanding of the patient's interpretation of her/his condition on the basis of the way in which the patient presents her/his problem, and that they orient their conduct to this interpretation also beyond the problem presentation phase. These observations give support to previous claims that the participants orient not only to the immediately prior discussion in the medical consultation but also to the overall structure of the consultation as a service encounter (Ruusuvuori 2000; Heritage and Maynard 2006). These findings have important implications for thinking about patient involvement in medical decision making.

\section{Data and method}

Data for the study consist of 86 primary care encounters video-recorded in nine municipal health centres in Finland in the years 2005-2006. The data include 46 child patients, 40 adult patients and 11 doctors. In each consultation the reason for the visit is an upper respiratory tract infection. All participating doctors, patients and parents were informed about the purpose of the study and gave their permissions for video-recordings. The study is approved by The Ethical Board of Pirkanmaa Health Care District (project R04143). Data excerpts in this article are translated from the original language, Finnish. The original data are obtainable from the authors.

The method of the study is conversation analysis (CA) (Sacks et al. 1974; Schegloff 2007). CA examines how sequencing of conversational actions, such as utterances and gestures, enables the participants to accomplish larger social activities, such as medical interviews. The present analysis focuses on the activities of problem presentation and diagnosis delivery. We detail how the different types of patients' problem presentation shape the doctors' ways of initiating the next activity after the problem presentation as well as delivering a diagnosis later on in the visit. As in the present data, the patients' concerns are similar; we are able to discern the different types of problem presentation and their consequentiality in terms of communicative conduct in the consultations.

\section{Types of problem presentation}

In their problem presentations, patients bring forward two kinds of information: symptoms and candidate diagnoses (Stivers 2002). In presenting their problems as 'symptoms only', patients may state I've had fever since Saturday and a bad cough. When patients compose their problem presentations around a 'candidate diagnosis', the symptoms are offered as grounds for the proposed diagnosis, as in I think it's sinusitis because I've got pressure here.

In a somewhat smaller number of cases, the problem presentation is more complex. In these cases, descriptions and explanations of symptoms get intertwined. For instance, a parent of a child patient may describe only one symptom by saying he complained about his ear yesterday, possibly implying an ear infection. Alternatively, patients may present background information about formerly diagnosed illnesses that may be relevant for their current conditions, for instance I've had sinus infections and now I have a feeling that this right side is totally congested. Table 1 outlines the distribution of these problem presentation types in our data (in frequencies and percentages).

In the data ( $n=86$ consultations), $35 \%$ of the patients' problem presentations were 'symptoms only', while $29 \%$ included a 'candidate diagnosis.' The next frequent type of problem presentation involved 'diagnosis implicative symptom descriptions' (24\%) while the least frequent type were the problem presentation in which the candidate diagnosis was given as 'background information' (12\%).

Now we turn to examine how the patient's choice of the type of problem presentation is consequential for the interaction in the examined encounters. First we describe the differences between 'symptoms only' 
Table 1: Distribution of problem presentation types

\begin{tabular}{lll}
\hline & F & $\%$ \\
Symptoms only & 30 & 35 \\
Candidate diagnosis & 25 & 29 \\
Diagnosis implicative symptom description & 21 & 24 \\
Candidate diagnosis as background information & 10 & 12 \\
Total & 86 & 100 \\
\hline
\end{tabular}

$n=86$ consultations

and 'candidate diagnosis' types of problem presentation and show that the doctors' communicative conduct following the problem presentation as well as in the diagnostic phase is systematically different depending on the patient's selection between these two types.

\subsection{Doctors' orientations to 'symptoms only'}

'Symptoms only' is the most frequent way for patients to present their problems (Ruusuvuori 2000; Stivers 2002; Heritage and Robinson 2006). In excerpt 1, the patient describes his illness in terms of everyday experience. Upon the completion of the presentation, the doctor initiates the next activity by launching her own line of medical reasoning.

\section{Excerpt 1a}

Problem presentation (Consultation 57)

01 D: $\quad$ yeah (.) so tell me,

$02 \quad(0.8)$

03 P: it's thi:s (.) pain in the chest

04 over (.) [here.

05 D: $[\mathrm{mm}::$ ?

$06 \quad(1.2)$

07 P: $\quad$ and (0.8) I- (.) am (.) am (.) I

08 haven't been feeling too good soh

$09 \mathrm{~h}(0.3)$ yesterday I went to: (.)

$10 \quad$ (lift) a rowboat but no (.)

11 indeed $<$ I was sweating all ${ }^{\circ}$ over $^{\circ}$.

$12 \quad(0.4)$

13 .hh[h (ind-)

14 D: [is there something that has

The patient initiates his problem presentation by describing his subjective symptom experience and the location of the symptom (1.3-4), and then continues with a narrative on how the problem emerges in his daily life (1. 7-11) (Ruusuvuori 2000: 136). After the patient completes his turn (Sacks et al. 1974), the doctor initiates a verbal examination by questioning the patient about his medical history (1. 14-15). The

doctor's initiation of the next activity follows her own medical reasoning instead of addressing any particularities in the patient's problem presentation. This becomes salient when we compare the symptomsonly type of problem presentation to those involving a candidate diagnosis.

Such 'independence' from the patient's problem presentation is visible also when doctors deliver diagnoses after 'symptoms only' presentations. Consider the next excerpt drawn from the same consultation as the excerpt examined above. It takes place just following the physical examination. In the beginning of excerpt $1 \mathrm{~b}$, the doctor asks about the patient's current medication and delivers the diagnosis thereafter.

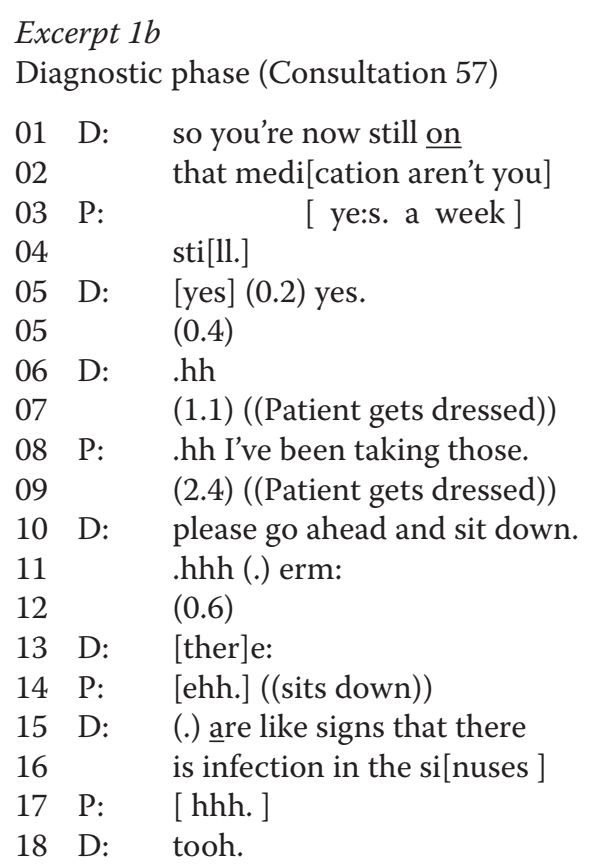

This is an example of a 'default' way of diagnosis delivery in symptoms-only cases in which the diagnosis is given as news to the patient (Heath 1992; Peräkylä 1998). The doctor starts her utterance with there (1.13) and pauses for a moment while the patient sits down (1. 14). As she continues, the slight stress 
on the word are (1.15) retrieves the cut-off utterance. The clinical observation the doctor makes, there are like signs (1. 13-15), serves as clinical grounds for the doctor's conclusion: there is infection (1. 15-16). Thus, the diagnosis is delivered as being based on the examination the doctor has made; it does not involve references to what the patient said in his problem presentation. A similar trajectory of interaction can be found in the next example.

\section{Excerpt $2 a$}

Problem presentation (Consultation 87)

\begin{tabular}{|c|c|c|}
\hline 01 & D: & $\begin{array}{l}<\text { what's }>\text { hhh }(0.2) \text { going on? } \\
((\text { mutual gaze }))\end{array}$ \\
\hline 02 & P: & well this, (.) sore throat? \\
\hline 03 & & (0.2) then \# erm, (.) it's painful \\
\hline 04 & & to swallow and,\# (0.2) I can't \\
\hline 05 & & eat properly. \\
\hline 06 & & $(0.2)(($ Doctor takes notes, nods $))$ \\
\hline 07 & P: & very little? \\
\hline 08 & & $(0.4)(($ Doctor writes $))$ \\
\hline 09 & D: & yea-h? \\
\hline 10 & $\mathrm{P}$ & and then I've had fever in the \\
\hline 11 & & past few days and, $(0.4)$ \\
\hline 12 & & a headache. \\
\hline 13 & & $\begin{array}{l}(1.2) \text { ((Doctor nods, completes } \\
\text { writing and moves gaze to } \\
\text { Patient)) }\end{array}$ \\
\hline 14 & D: & what else. ((mutual gaze)) \\
\hline 15 & P: & I don't remember if there \\
\hline 16 & & was anything else. \\
\hline 17 & & $(0.2)$ \\
\hline 18 & D: & .hhh $(0.4)$ for how many days \\
\hline 19 & & you've had a sore throat. \\
\hline
\end{tabular}

The patient (a 15-year old girl) initiates her problem presentation by locating her problem (sore throat, 1.2) and by describing how the problem affects her daily life (1.3-7). While listening, the doctor takes notes and encourages the patient to continue $(1.6,9)$. The patient mentions two other symptoms, fever and headache (1. 10-12). After the patient has arrived at the completion of her telling (1. 12-13) (Sacks et al. 1974), the doctor receives the problem presentation minimally, by nodding (1. 13) and thereafter offers the patient a chance to continue by asking what else (1. 14). The patient does not recollect any other problems, and the doctor initiates the next activity with a verbal examination question (1. 18-19). This question directs the attention to the duration of the patient's symptoms and thus it launches the doctor's line of medical reasoning.

Communication in the diagnostic phase of this consultation also follows the doctor's medical reasoning. In the beginning of the next excerpt (2b) the doctor palpates the patient's lymph nodes and delivers the diagnosis thereafter (1.3).

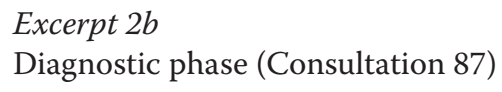

The doctor's turn-initial well (1. 3) directs the attention to a new activity, diagnosis delivery, after the physical examination. He delivers the diagnosis as a 'plain, factual assertion': this is a viral illness or a bacterial illness (Heath 1992; Peräkylä 1998). In so doing, the doctor communicates the diagnosis as his own conclusion rather than addressing something the patient would have suggested. After giving the two possible options for the diagnosis, the doctor tells the patient and the patient's mother (note the doctor's glance at 1. 9) that no medical treatment is available for a viral illness (1. 6-8). Thereafter, he introduces another diagnostic option, mononucleosis (1. 11), and starts questioning the patient on other possible symptoms (1. 11-12).

In sum, symptoms-only type of problem presentations concerns patients' subjective accounts of their ilness experiences. In receiving these presentations as well as in initiating the next activity, the doctors do not address any particularities in the patient's problem presentation but follow their own lines of medical reasoning. Similarly, in delivering diagnoses in these consultations, the doctors indicate that the diagnosis is based on their own reasoning instead of something that the patient would have suggested. Thus, interaction in these key junctures of consultation follows a conventional 'doctor-directed' conduct emphasizing the doctor's medical authority and the patient's position as an information provider (in the problem presentation phase) and information receiver (in the diagnostic phase) (cf. Collins 2005; Collins et al. 2005). In contrast, the patient's 'candidate diagnosis' engenders a quite different trajectory of interaction. 


\subsection{Doctors' orientations to 'candidate diagnosis'}

'Candidate diagnoses' are patients' own suggestions for the explanation of illness (ten Have 2001; Stivers 2002; cf. Gill 1998). When patients produce candidate diagnoses in their problem presentations, doctors frequently address them in the encounter: in their immediately following actions after the problem presentation, and also later on, in delivering a diagnosis. Consider the next example.

\section{Excerpt $3 a$}

Problem presentation (Consultation 10)

01 D: yea:h?, (0.3) what's (.) what's

$02 \quad{ }^{\circ} \mathrm{up}^{\circ},(($ Doctor sits down $))$

$03 \quad$ (0.3) ((mutual gaze))

$04 \quad$ P: $\quad$ well $\uparrow I$ thi $\uparrow$ nk I've got sinus

05 infection because I have pressure

06 here and phlegm is all green

07 (.) ((Patient points to cheekbones))

08 P: and it doesn't run easily

09 the[re so,]

10 D: [Eyour vo]ice is a bit

11 [ ${ }^{\circ}$ odd $^{\circ} . £$ ]

12 P: [£a bit ]

13 od[d£ yeah ]

14 D: [.h so that kind of]

15 voice the sound [that you]

16 P: [ mm:, ]

17 D: may have it indeed, ((turns toward a computer))

The patient produces a candidate diagnosis as a first part of her problem presentation: well I think I've got sinus infection (1. 4-5) (Stivers 2002). This serves as a gloss (Jefferson 1985) which is thereafter unpacked in the turn continuation as the patient presents evidence for her diagnostic suggestion: because I have pressure here and the phlegm is all green and it doesn't run easily (1. 5-9). The doctor addresses the candidate diagnosis immediately by reporting his own observation about the patient's atypical voice, a symptom that fits into the proposed candidate diagnosis (l. 10-11). The patient confirms this observation (1. 12-13). Thereafter, the doctor further evaluates the accuracy of the patient's candidate diagnosis, you may have it indeed, thereby explicitly relating his observation to the patient's diagnostic suggestion (1. 14-17) (cf. Jones 2001). In other words, in receiving the problem presentation, the doctor addresses the particularities the patient brought forward instead of launching an 'independent' line of medical reasoning found in symptoms-only consultations.
The next extract (3b) from the same consultation shows how the doctor orients to the patient's candidate diagnosis as he initiates the physical examination and then delivers the diagnosis. In the beginning of the extract the doctor starts an ultrasound examination of the patient's sinuses.

\begin{tabular}{|c|c|c|}
\hline & & \\
\hline 02 & & side at thrst \\
\hline 03 & & (1.5) ((Doctor examines)) \\
\hline 04 & D: & there's no illness here=the \\
\hline 05 & & membrane is just a bit thicker \\
\hline 06 & & .hh (.) I'll try it from this \\
\hline 07 & & side then I use the same gel \\
\hline 08 & & †again. \\
\hline 09 & & (2.8) ((Doctor examines)) \\
\hline 10 & D: & there is an illness he:re. \\
\hline 11 & & (2.5) ((Doctor examines)) \\
\hline 12 & P: & it hurts more on that side too. \\
\hline 13 & & (0.9) ((sinus exam ends)) \\
\hline
\end{tabular}

The initiation of the physical examination displays the doctor's orientation to the patient's candidate diagnosis. First, he starts the activity with ultrasound examination of the patient's sinuses, thereby treating the sinuses as the first priority. Second, his utterance, let's look at the healthier side first (1. 1-2), explains his action with reference to the patient's candidate diagnosis, already treating the other sinus as possibly or probably infected.

While examining the patient, the doctor first disconfirms the presence of 'illness' in one sinus (l. 4) and then confirms its presence on the other side (1. 10). The reference to 'illness' invokes the patient's candidate diagnosis as the doctor stresses the words no (l. 4) and is (1. 10) in reporting the findings (cf. Heritage and Stivers 1999). Thereby, the doctor does not only mark the contrast between his negative and positive findings, but frames his commentary as a confirmation of the patient's candidate diagnosis (Stivers 2002). The patient receives the diagnosis with further evidence: it hurts more on that side too (1. 12). The same kind of orientation to a candidate diagnosis is noticeable also in the next example.

\section{Excerpt $4 a$}

Problem presentation (Consultation 17) (F = father)

01 D: okay[:h wh]at's with Taavi.,

02 F: $\quad[\operatorname{lady}()](($ talks to the

03 child))

04 F: $\quad$ Taavi has had sniffles? $<(0.5)$

05 .hh for a week now?

$06 \quad(0.2)$ 
07

9 F: erm, (0.6) .hh now it's been

10 a couple of ni< erm nights or

11 early< erm nights he's been

12 crying =right after he lies

13

14

15

16

17

$18 \mathrm{D}$

19 F:

20

21 D: we[ll ] (.) judged=has he been

22 F: $\quad[\uparrow \mathrm{mmh}$.]

23 D: <个coughing $>$ a lot or,

This excerpt shows another way in which a candidate diagnosis can be proposed. First, the father presents the baby's symptoms as evidence for his upcoming suggestion (1.3-13) after which the candidate diagnosis is produced as a conclusion (1. 15-16). The first part of the father's turn, Taavi has had sniffles for a week now, works as a title (l. $3-4)$, not as an adequate problem presentation as such. The doctor encourages the father to continue (l. 7), after which the father tells how the child's problem emerges and specifies the actual situation when the child starts crying (1. 8-13). After the doctor has received the father's telling as complete (l. 14), the father once more takes the turn and offers a summary of his problem presentation. Now he proposes an explanation for the baby's crying: he could have something in his ears (1. 15-16). The father's choice of the word 'something', rather than 'ache' or 'pain', suggests that he is not only talking about the child's experience but about something that causes it, i.e. he implies an ear infection as a candidate diagnosis (Stivers 2002).

The father's diagnostic implication is manifested in the doctor's next actions (1. 17, 20). The doctor's turn-initial nii-particle treats the father's cautious suggestion as a possibility but does not necessarily agree with it. Instead it supports the father's right to present diagnostic claims (Sorjonen 2001: 132-137). In addition, prior to initiating the investigation phase, the doctor assesses the father's suggestion: well quite well judged (1. 20) (cf. Jones 2001).

The next extract (4b) shows how the diagnosis is delivered in this consultation. In the beginning of the extract, the doctor has completed the examination of the child's left ear and is currently examining his right ear.
Excerpt $4 b$

Diagnostic phase (Consultation 17)

01 ((Doctor examines))

02 D: [well it's indeed<

03 P: ääghh

04 (.)

$05 \mathrm{~F}$ : $\quad$ this is infec ${ }^{\circ}$ ted $^{\circ}$.

06 D: yeah it's li[ke

07 P: $\quad[\mathrm{mh}$

08 D: $\quad$ wrinkle $[\mathrm{d}<$ and red, ((examines))

09 F: $\quad$ [yes. ((ear exam ends))

10 D: so that $i<$ it's not (0.4) like

11 there isn't terribly lot of

12 discharge but indeed when

13 [he $<$ ] lies do[wn the

14 F: [yeah.] [exactly.,

15 D: the pressure comes \#from there

16 soh,\#

The excerpt reveals the participants' mutual orientation towards the father's candidate diagnosis. To begin with, the doctor presents online commentary of clinical findings of the ear examination (Heritage and Stivers 1999). Being occupied with the examination, she cuts her turn off (1. 2). However, with her utterance, it's indeed, she seems to initiate a confirmation of the father's proposal rather than just commenting on the findings. Thereafter, the father suggests a version of what the doctor implied in the incomplete turn and uses an explicit diagnostic category infected (1.5). The doctor confirms this while she is still examining the patient's ear (1.6). She describes her observations that confirm the suggested diagnosis (1. 8) and further elaborates on the line of reasoning that the father had brought about in the problem presentation: the child crying while lying down is being related to the problems in the ear (1. 11-12, 15).

In sum, in consultations where the patients/parents propose candidate diagnoses, the doctors maintain their orientations to such presentations. In receiving the problem presentation, the doctors take up the candidate diagnosis by commenting upon some aspect of it. Moreover, in the verbal/physical examination after the problem presentation, the doctors display their actions as being connected to the patient's problem presentation. Finally, the doctors deliver the diagnosis as if confirming the patient's candidate diagnosis (or in some cases, disconfirming it). As the doctors orient to the patient's problem presentation also beyond its immediate context, their communicative conduct thus involves the patient's/parent's point of view, implementing a more patient-participatory way of consultation (cf. Hamilton 2004; Collins et al. 2005).

Up to this point, we have examined consultations with two most frequent types of problem 
presentation: 'symptoms only' vs. 'candidate diagnoses.' Next we consider the more complex problem presentation types: 'diagnosis implicative symptom descriptions' and 'candidate diagnosis as background information'. By giving one typical example of each type, we show how in these problem presentations the descriptions of symptoms and the patients' diagnostic ideas get intertwined, and how doctors respond to these problem presentations.

\subsection{Doctors' orientations to 'diagnosis implicative symptom descriptions'}

Diagnosis implicative symptom description (appearing mostly in child patient visits: 17 out of 21 cases) typically includes only one symptom that the patient/ parent presents, such as ear pain implying an ear infection. These presentations can be treated as 'symptoms only' by doctors. However, doctors typically orient to them as implying a candidate diagnosis. Excerpt 5 provides an example.

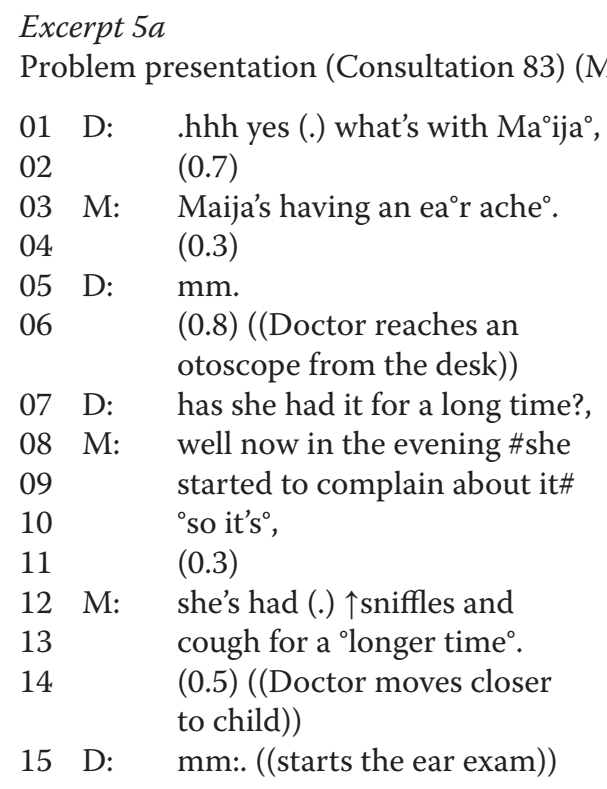

The mother presents her child's problem by specifying only one symptom and marks this symptom description as being adequate. Maija's having an ear ache is a full sentence that ends with terminal intonation and soft voice indicating the completion of her telling (1. 3) (Sacks et al. 1974). The gap following the turn also shows that the mother is ready to pass the turn to the doctor (1. 4). The doctor orients to the problem presentation as adequate. She receives the mother's turn minimally (1.5) and then reaches for an otoscope from the desk (1. 6), getting ready to examine the child's ears. Also her first verbal examination question addresses the ear ache (1.7). Thus, the doctor's actions following the problem presentation focuses directly on the examination of this particular symptom. In the next excerpt from the same consultation (5b), the doctor delivers the diagnosis while the ear examination is still under way.

\begin{tabular}{|c|c|c|}
\hline \multicolumn{3}{|c|}{$\begin{array}{l}\text { Excerpt } 5 b \\
\text { Diagnostic phase (Consultation } 83 \text { ) }\end{array}$} \\
\hline 01 & & (9.0) ((Doctor examines)) \\
\hline $\begin{array}{l}02 \\
03\end{array}$ & D: & $\begin{array}{l}\text { \#it's really heavily infec\#ted } \\
\text { that }^{\circ} \text { ear, }\end{array}$ \\
\hline 04 & & (.) \\
\hline $\begin{array}{l}05 \\
06\end{array}$ & D: & $\begin{array}{l}\text { show me the other one, } \\
(0.5)((\text { child turns }))\end{array}$ \\
\hline $\begin{array}{l}07 \\
08\end{array}$ & D: & $\begin{array}{l}\text { it's: \#really red and swol }{ }^{\circ} l e{ }^{\circ} \text {. } \\
\text { (0.5) ((Doctor examines)) }\end{array}$ \\
\hline $\begin{array}{l}09 \\
10\end{array}$ & M: & $\begin{array}{l}\text { yeah that one she complains } \\
\text { 'about }{ }^{\circ} \text {. }\end{array}$ \\
\hline 11 & D: & \#yeah.\# \\
\hline 12 & & (3.7) ((Doctor examines)) \\
\hline $\begin{array}{l}13 \\
14\end{array}$ & D: & $\begin{array}{l}\text { this one doesn't look too bad, } \\
\text { (1.6) ((ear exam ends)) }\end{array}$ \\
\hline
\end{tabular}

The doctor delivers the diagnosis while still examining the child's ear (1. 2-3). Her turn is a confirmatory announcement with respect to the mother's problem presentation. In her turn-design, it's really heavily infected, the doctor gives the first priority to the quality of infection instead of just informing about the presence of an ear infection. Thus, she treats the diagnosis being not news to the mother as such. As the child is turning her other ear to be examined by the doctor, the doctor further elaborates the finding to the mother (1.7). The mother confirms the diagnosis and the findings with her own knowledge of the child's symptom (1. 9-10).

In sum, in diagnosis implicative symptom descriptions, patients typically mention only one symptom and treat it as an adequate problem presentation. This 'specific' symptom may imply but does not make explicit claims about diagnoses. The doctors, however, most typically treat them as implied candidate diagnoses and act responsively.

The last type of problem presentation found in our data is 'candidate diagnosis as background information', which we examine next.

\subsection{Doctors' orientations to 'candidate diagnosis as background information'}

Alongside symptom descriptions, patients may provide background information about formerly diagnosed illnesses or other diagnostic categories that may be relevant for their current conditions. In doing so, patients embed the candidate diagnosis 
in their problem presentation but do not present it as the primary concern (as in examples 3 and 4). In turn, most often doctors do not address these candidate diagnoses in their next actions. Interestingly though, they do so later on in the consultation, in delivering a diagnosis. Consider the following example.

\section{Excerpt $6 a$}

Problem presentation (Consultation 62)

01 D: well what brings you here,

$02 \quad(0.7)$

03 P: well I have a prolonged cough

04. So that last night I did nothing

05 but coughing all the time

06 actually I haven't slept almost

07 at all so that it's been over a

08 week now,

$09 \quad(0.4)$

10 D: $\mathrm{mm} \downarrow::$ ?

11 (.)

12 P: like that.

$13 \quad(1.2)$

14 D: ho[w did it]

15 P: [a:nd ]

16 (.)

7 D: yeah?

$18 \quad(0.2)$

19 P: $\quad$ so that I've got asthma and (0.5)

20 so it effects right away that I

21 have lo- (.) I've had sinus

22 infections and, (.) .hh (0.6) and

23 I've got here also (0.3) feeling

24 that at least this right side is

25 like totally congested.

26 (.)

27 D: mm:?,

$28 \quad(0.7)$

29 D: .hh (.) erm how did it begin did

it start with cough sniffles or

did you have like \# e\# (.) throat ache first?

The candidate diagnosis is embedded in the patient's problem presentation but not in the way that the patient would claim it straightforwardly. The first part of the patient's turn involves a description of cough and troubled sleeping (1. 3-12). After a long gap at talk (1. 13), the doctor is about to start a verbal examination (1. 14). However, the patient continues and the doctor cuts her own turn off (1.15). The doctor encourages the patient to continue (1.17), after which the patient provides background information about her chronic disease, asthma (l. 19-20), and connects it to her recurrent sinus infections (1. 20-22). After providing this information, the patient returns to her current symptoms (Robinson and Heritage 2005) and then completes her telling (1. 22-25).

The doctor receives the problem presentation minimally (1.27) and initiates the verbal examination by focusing on her line of medical investigation (1. 29-32). Nevertheless, as she delivers the diagnosis in the consultation, she addresses the candidate diagnosis that was embedded in the patient's problem presentation.

Excerpt $6 b$

Diagnostic phase (Consultation 62)

$01 \quad$ (0.3) ((stethoscope exam ends))

02 D: yea::h?, (.) .hh so that of

03 course those \# e-\# (0.3) those

04. symptoms and (.) and then the

05 ultra sound \#e-\# (0.5) finding

06 and of course the phlegm in your

07 throat would indeed fit to the

08 sinus infection,

In delivering the diagnosis, the doctor addresses the embedded candidate diagnosis in the patient's problem presentation by referring to those symptoms (1. 3-4), admitting that of course $(1.2-3,6)$ the symptoms and findings fit to the sinus infection (1. 7-8). She also uses the adverb indeed (1. 7) in a confirmatory manner. Thus, the doctor evokes the patient's embedded explanation of symptoms (sinus infection) in designing the diagnosis delivery, even though she disregarded it at first mention.

In sum, following candidate diagnosis that is presented as background information doctors tend not to address it in their immediately next actions. However, these candidate diagnoses, even though being only embedded in the patient's problem presentation, are frequently addressed in the ways in which doctors deliver diagnoses. This way, the doctors' communicative conduct vacillates between the two patterns that are instigated by the 'symptoms only' and 'candidate diagnosis' types of problem presentation.

\section{Summary}

The following Tables 2 and 3 show how the doctors systematically address the patients' problem presentations in the ways described above. Table 2 summarizes the doctors' immediate actions following the problem presentation.

When patients present 'symptoms only', in 24 out of 30 cases the doctor receives it and initiates the 
Table 2: Doctors' next actions after the problem presentation

\begin{tabular}{lccc}
\hline & No reference & Reference & Total \\
\hline Symptoms only & 24 & 6 & 30 \\
Candidate diagnosis & 4 & 21 & 25 \\
Diagnosis implicative symptom description & 7 & 14 & 21 \\
Candidate diagnosis as background information & 7 & 3 & 10 \\
\hline
\end{tabular}

$n=86$ consultations

Table 3: Doctors' actions in the diagnostic phase

\begin{tabular}{lccc}
\hline & No reference & Reference & Total \\
\hline Symptoms only & 24 & 6 & 30 \\
Candidate diagnosis & 3 & 22 & 25 \\
Diagnosis implicative symptom description & 2 & 19 & 21 \\
Candidate diagnosis as background information & 1 & 9 & 10 \\
\hline
\end{tabular}

$n=86$ consultations

next action without addressing the problem presentation as such. The communicative conduct is quite the opposite when the patient presents a candidate diagnosis. In 21 out of 25 cases the doctors assess or otherwise address it in their immediately following actions. The doctors' orientations are more varied with more complex problem presentation types. They typically refer to 'diagnosis implicative symptom descriptions' in their next actions (14 out of 21 cases). In turn, when the candidate diagnosis is presented as background information, the doctors tend not to address it immediately (seven out of ten cases).

The distinct trajectories of interaction observed in the problem presentation and reception are visible in the diagnostic phases of the examined consultations, too. Consider Table 3.

Following a symptoms-only type of problem presentation, in 24 out of 30 cases the doctor does not address it in the diagnostic phase but delivers the diagnosis as being based on her/his own medical reasoning. In contrast, in 22 out of 25 cases following the patient's candidate diagnosis, the doctor addresses it in a (dis)confirmatory manner in delivering the diagnosis. The same goes for the latter two types of problem presentation. In 19 out of 21 cases of 'diagnosis implicative symptom description' and in nine out of ten cases of 'candidate diagnosis as background information', the doctor designs the diagnosis delivery to be responsive to the patient's problem presentation, not based on her/his own medical reasoning only.

\section{Discussion}

It is evident that doctors have primary control over the initiation of the next activities following the problem presentation in medical consultations. However, we have shown that the doctors incorporate their patients' views that were established in the problem presentation phase in these next activities. This observation adds to our previous understanding of diagnosis delivery in medical consultation. Heath (1992) found that the form of diagnosis delivery as factual assertion does not encourage patient involvement but maintains the doctor's authority and the patient's subordinate position in the consultation. Later, Peräkylä (1998) showed that doctors do not rely solely on their medical authority in delivering diagnoses but also treat themselves as accountable for providing the patient with an evidential basis for the diagnosis. In this study, as the doctors design their diagnosis deliveries to be responsive to the patient's problem presentation, they do not rely on their medical expertise only but orient to and treat themselves accountable for meeting the patient's own understanding of her/his condition.

Following a 'symptoms only' presentation, doctors do not treat themselves as interactionally accountable to address the patient's problem presentation. However, they do so in delivering a diagnosis that follows the patient's candidate diagnosis. Thus, the patients' problem presentations are shown to establish a certain trajectory of interaction in the visit which the doctors are responsive to. This trajectory 
that is found in Finnish adult and paediatric GP consultations for upper respiratory tract infections is very similar to the one found by Stivers (2002) in paediatric consultations with similar problems in the USA. These similarities suggest that patients and doctors in both countries orient to a profound interactional structure of 'request and granting' as the overall structure of acute primary care visits within the studied context.

This observation adds to the discussion on 'doctorcentred' vs. 'patient-centred' communication in medical care. Recently, Collins et al. (2005) found two different types of physician practices with regard to treatment decision-making and patient participation. In the bilateral approach, the practitioners actively pursue and receive more patient contributions whereas in the unilateral approach they encourage the patients' involvement less, and consequently, patients indeed respond less to the treatment decisions. Thus, the doctor's selection of communication pattern has an influence on patient participation (see also Collins 2005). The present study shows that, in turn, the patient's selection of problem presentation type has an influence on the doctors' conduct. Following a symptoms-only type of problem presentation, the doctors resort to the 'unilateral' style of consultation that leaves little space or relevance for patient participation. In contrast, following the patient's 'candidate diagnosis', the doctors systematically maintain the patient's point of view in delivering the diagnosis, thereby engaging their conduct in the 'bilateral' style of consultation (cf. Collins et al. 2005). As the summarizing Tables 2 and 3 showed, in our data the doctors modify their actions rather systematically with regard to the patient's initial conduct, indicating that the patient's problem presentation has substantial influence on the doctors' selection of communication trajectories, also beyond the initial phase of consultation.

The above findings have implications for medical training and clinical practices. First, the educational use of patient-centred models of communication, such as shared decision making and concordance (see e.g. Bissell 2004), could benefit from paying attention to the consultation as a whole, not just to one phase of it (such as diagnosis delivery or decision-making). Second, by recognizing their ways of responding to the patients' problem presentations, the practitioners could engage in more patient-centred communication in consultations. This includes meeting the patients' subjective experiences even though the patient would not present candidate diagnosis as well as being open to a potential range of concerns even though the patient would present himself/herself as having a particular diagnosis in mind.

This study provides evidence on how communication in one location, problem presentation, shapes interaction also in the diagnostic phase of consultation. We have thus seen how the understanding of the patient's condition is co-constructed in the encounter. What seems to be an established interactional trajectory in primary care consultations warrants further research in different clinical settings, such as consultations for chronic diseases.

\section{References}

Barry, C., Stevenson, F., Britten, N., Barber, N. and Bradley, C. (2001). Giving voice to the lifeworld. More humane, more effective medical care? A qualitative study of doctor-patient communication in general practice. Social Science E Medicine 53 (4): 487-505. doi:10.1016/S0277-9536(00)00351-8

Bissell, P. May, C. and Noyce, P. (2004). From compliance to concordance: Barriers to accomplishing a re-framed model of health care interactions. Social Science E Medicine 58 (4): 851-862. doi:10.1016/S02779536(03)00259-4

Byrne, P. and Long, B. (1984 [1976]). Doctors Talking to Patients: A Study of the Verbal Behaviours of Doctors in the Consultations. London: Her Majesty's Stationery Office.

Collins, S. (2005). Communicating for a clinical purpose: Strategy in interaction in healthcare consultations. Communication E Medicine 2 (2): 111-122. doi:10.1515/ come.2005.2.2.111

Collins, S., Britten, N., Ruusuvuori, J. and Thompson, A. (2007). Understanding the process of patient participation. In S. Collins, N. Britten, J. Ruusuvuori and A. Thompson (eds) Patient Participation in Health Care Consultations. Qualitative Perspectives, 3-21. Maidenhead: Open University Press.

Collins, S., Drew, P., Watt, I. and Entwistle, V. (2005). 'Unilateral' and 'bilateral' practitioner approaches in decisionmaking about treatment. Social Science E Medicine 61 (12): 2611-2617. doi:10.1016/j.socscimed.2005.04.047

Gill, V. (1998). Doing attributions in medical interaction: Patients' explanations for illness and doctors' responses. Social Psychology Quarterly 61 (4): 342-360. doi:10.2307/2787034

Hamilton, H. (2004). Symptoms and signs in particular: The influence of the medical concern on the shape of physician-patient talk. Communication $\mathcal{E}$ Medicine 1 (1): 59-70. doi:10.1515/come.2004.006

Heath, C. (1992). The delivery and reception of diagnosis in the general-practice consultation. In P. Drew and J. Heritage (eds) Talk at Work. Interaction in Institutional Settings, 235-267. Cambridge: Cambridge University Press. 
Heritage, J. and Maynard, D. W. (2006). Introduction: Analyzing interaction between doctors and patients in primary care encounters. In J. Heritage and D. Maynard (eds) Communication in Medical Care. Interactions between Primary Care Physicians and Patients, 1-21. Cambridge: Cambridge University Press.

Heritage , J. and Robinson, J. (2006). Accounting for the visit: Giving reasons for seeking medical care. In J. Heritage and D. Maynard (eds) Communication in Medical Care. Interactions between Primary Care Physicians and Patients, 48-85. Cambridge: Cambridge University Press.

Heritage, J. and Stivers, T. (1999). Online commentary in acute medical visits: A method of shaping patient expectations. Social Science E Medicine 49 (11): 1501-1517. doi:10.1016/S0277-9536(99)00219-1

Jefferson, G. (1985). On the interactional unpackaging of a 'gloss'. Language in Society 14 (4): 435-466. doi:10.1017/ S0047404500011465

Jones, C. (2001). Missing assessments: Lay and professional orientations in medical interviews. Text $21(1 / 2)$ : 113-150.

Peräkylä, A. (1998). Authority and accountability: The delivery of diagnosis in primary health care. Social Psychology Quarterly 61 (4): 301-320. doi:10.2307/2787032

Roberts, C., Sarangi, S. and Moss, B. (2004). Presentation of self and symptoms in primary care consultations involving patients from non-English speaking backgrounds. Communication \& Medicine 1 (2): 159-169. doi:10.1515/ come.2004.1.2.159

Robinson, J. (2003). An interactional structure of medical activities during acute visits and its implications for patient participation. Health Communication 15 (1): 27-57. doi:10.1207/S15327027HC1501_2

Robinson, J. and Heritage, J. (2005). The structure of patient's presenting concerns: The completion relevance of current symptoms. Social Science E Medicine 61 (2): 481-493. doi:10.1016/j.socscimed.2004.12.004

Ruusuvuori, J. (2000). Control in Medical Consultation. Practices of Giving and Receiving the Reason for the Visit in Primary Health Care. Tampere: Acta Universitatis Tamperensis 16.

Sacks, H., Schegloff, E. and Jefferson, G. (1974). A simplest systematics for the organization of turntaking for conversation. Language 50 (4): 696-735. doi:10.2307/412243

Schegloff, E. (2007). Sequence Organization in Interaction. A Primer in Conversation Analysis. Vol. 1. Cambridge: Cambridge University Press. doi:10.1017/ CBO9780511791208
Sorjonen, M-L. (2001). Responding in Conversation: A Study of Response Particles in Finnish. Amsterdam: Benjamins.

Stevenson, F., Barry, C., Britten, N., Barber, N. and Bradley, C. (2000). Doctor-patient communication about drugs: The evidence for shared decision making. Social Science E Medicine 50 (6): 829-840. doi:10.1016/ S0277-9536(99)00376-7

Stivers, T. (2002). Presenting the problem in pediatric encounters: 'Symptoms only' versus 'candidate diagnosis' presentations. Health Communication 14 (3): 299-338. doi:10.1207/S15327027HC1403_2

ten Have, P. (2001). Lay diagnosis in interaction. Text 21 (1/2): 251-260.

Thompson, A. (2007). The meaning of patient involvement and participation in health care consultations: A taxonomy. Social Science E Medicine 64 (6): 1297-1310. doi:10.1016/j.socscimed.2006.11.002

Taru Ijäs-Kallio is a graduate student in social psychology in the Department of Social Research, University of Tampere. She is writing a doctoral dissertation on diagnostic and treatment decision-making in Finnish primary care consultations. Her research interests include interactional constituents of patient participation and professional-client relationship in health care. Address for correspondence: Department of Social Research, 33014 University of Tampere, Finland. Email: taru.ijas@uta.fi

Johanna Ruusuvuori is a senior assistant professor in social psychology in the Department of Social Research, University of Tampere. Her research interests include medical interaction, emotion in social interaction, changing professional-client relations in various contexts of health care, and the role of facial expression in face-to-face interaction. Address for correspondence: Department of Social Research, 33014 University of Tampere, Finland. Email: johanna.ruusuvuori@uta.fi

Anssi Peräkylä is a professor of sociology in the Department of Sociology, University of Helsinki. His current research interests include interaction in medical consultations and psychotherapy. He is also studying facial expressions in emotional interaction and interaction and emotion between a baby and a care-taker. Address for correspondence: Department of Sociology, 00014 University of Helsinki, Finland. Email: anssi.perakyla@helsinki.fi 